\title{
The Falcon Curve: Implications of Seasonal Building Energy Use and Seasonal Energy Storage for Healthy Decarbonization
}

Jonathan Buonocore ( $\sim$ jbuonocore@mail.harvard.edu )

Center for Climate, Health, and the Global Environment, Harvard T.H. Chan School of Public Health https://orcid.org/0000-0001-7270-892X

Parichehr Salimifard

Department of Environmental Health, Harvard T.H. Chan School of Public Health

Zeyneb Magavi

HEET

Joseph Allen

Department of Environmental Health, Harvard T.H. Chan School of Public Health

Article

Keywords:

Posted Date: February 8th, 2022

DOI: https://doi.org/10.21203/rs.3.rs-1054606/v1

License: (a) (i) This work is licensed under a Creative Commons Attribution 4.0 International License. Read Full License 
1 The Falcon Curve: Implications of Seasonal Building Energy Use and Seasonal Energy Storage

2 for Healthy Decarbonization

4 Jonathan J Buonocore, Parichehr Salimifard, Zeyneb Magavi, Joseph G. Allen

6 Nature Energy: 3000 words (containing an intro $<500$ words) +3000 words for methods, $\leq 8$

7 figures/tables, 150 word abstract

\section{Abstract}

11 Building electrification is essential to many full-economy decarbonization pathways. Current

12 decarbonization modeling does not incorporate fluctuations in building energy demand. U.S.

13 monthly average total building energy consumption varies by a factor of $1.6 x$-lowest in May

14 and highest in January. This is largely managed by fossil fuel systems with storage capability.

15 Under all prototypical coefficients of performance (COPs), electrifying buildings substantially

16 increases winter electrical demand, enough to switch the grid from summer to winter peaking.

17 Meeting this with renewables would require a $28 \mathrm{x}$ increase in January wind generation, or a

$18303 x$ increase in January solar, with excess generation in other months. Technologies with a

19 COP of 6 shrink the winter peak-requiring 4.5x more generation from wind and 36x more from 20 solar.

\section{Introduction}

23 To date, most full-economy decarbonization pathways have heavily relied on electrification of 24 energy use in buildings, transportation, and other sectors ${ }^{1,2}$. Full conversion from combustion 
energy sources would have public health benefits by averting air pollution emissions ${ }^{3}$. Existing

2 full-economy decarbonization pathway models generally use yearly resolution-they do not

3 incorporate monthly to seasonal variation in full energy demand, consequently overlooking

4 winter heating demand ${ }^{1,2,4-6}$. In the U.S., $12 \%$ of residential buildings and $9.5 \%$ of commercial

5 buildings use propane, oil, and/or wood, which can be stored on site or at distribution facilities,

6 as a primary heating fuel ${ }^{7,8}$. Natural gas is a primary heating fuel for $42 \%$ of commercial

7 buildings and $49 \%$ of residential buildings ${ }^{7,8}$. Natural gas also has a fleet of 388 active

8 underground gas storage (UGS) facilities around the U.S., along with liquefied natural gas

9 (LNG) facilities as part of its transmission and distribution system ${ }^{9,10}$. Successfully electrifying

10 buildings without relying on combustion fuels requires replacing the energy supplied by these

11 combustion sources along with their existing storage capability. To provide insight into potential

12 paths forward electrification of building heating, we examine the performance of the current

13 fossil-based system in the U.S. Specifically, we evaluate the seasonal patterns in production

14 and consumption of energy used for heating, with a focus on gas and the role of UGS facilities

15 in managing the asynchronicity between energy production and consumption. To do this, we

16 use monthly energy consumption, production, and gas flow data from the U.S. Energy

17 Information Administration (EIA) from January 1973 through February $2020^{9,11}$. We then

18 develop some illustrative scenarios of how electricity demand could change as buildings are

19 electrified using different coefficients of performance (COPs) as benchmarks ${ }^{12-15}$, and the

20 extent of renewable energy buildout that is necessary to meet this demand.

\section{The Falcon Curve - Current Seasonal Fluctuations in Building Total Energy Use}

24 Energy use in residential and commercial buildings have changed substantially over the last 50

25 years (Fig 1). Electricity use and accompanying losses have increased from 1973 to 2010, and

26 plateaued or decreased slightly since 2010; use of natural gas in commercial buildings has gone 
1 up slightly, and stayed roughly the same in residential buildings (Figs 1A and 1B). All energy

2 types have substantial seasonal variability in consumption, with a monthly profile resembling a

3 falcon (Fig 1C and 1D)_Peak total energy consumption occuring in December and January

4 (heating season), a secondary peak in July and August (cooling season), and lowest in the

5 transitional months April, May, September, and October. Monthly average total energy usage is

6 lowest in May for residential buildings at 1,205 trillion Btus (TBtus), and lowest in September for

7 commercial at 1,102 TBtus. Usage is highest in January, at 2,270 TBtus for residential and

81,466 for commercial. Gas responds to $77 \%$ of this increase in demand-increasing by 761

9 TBtus for residential buildings from August to January, and 338 TBtus for commercial buildings

10 from January to July (Fig $1 \mathrm{C}$ and D). 

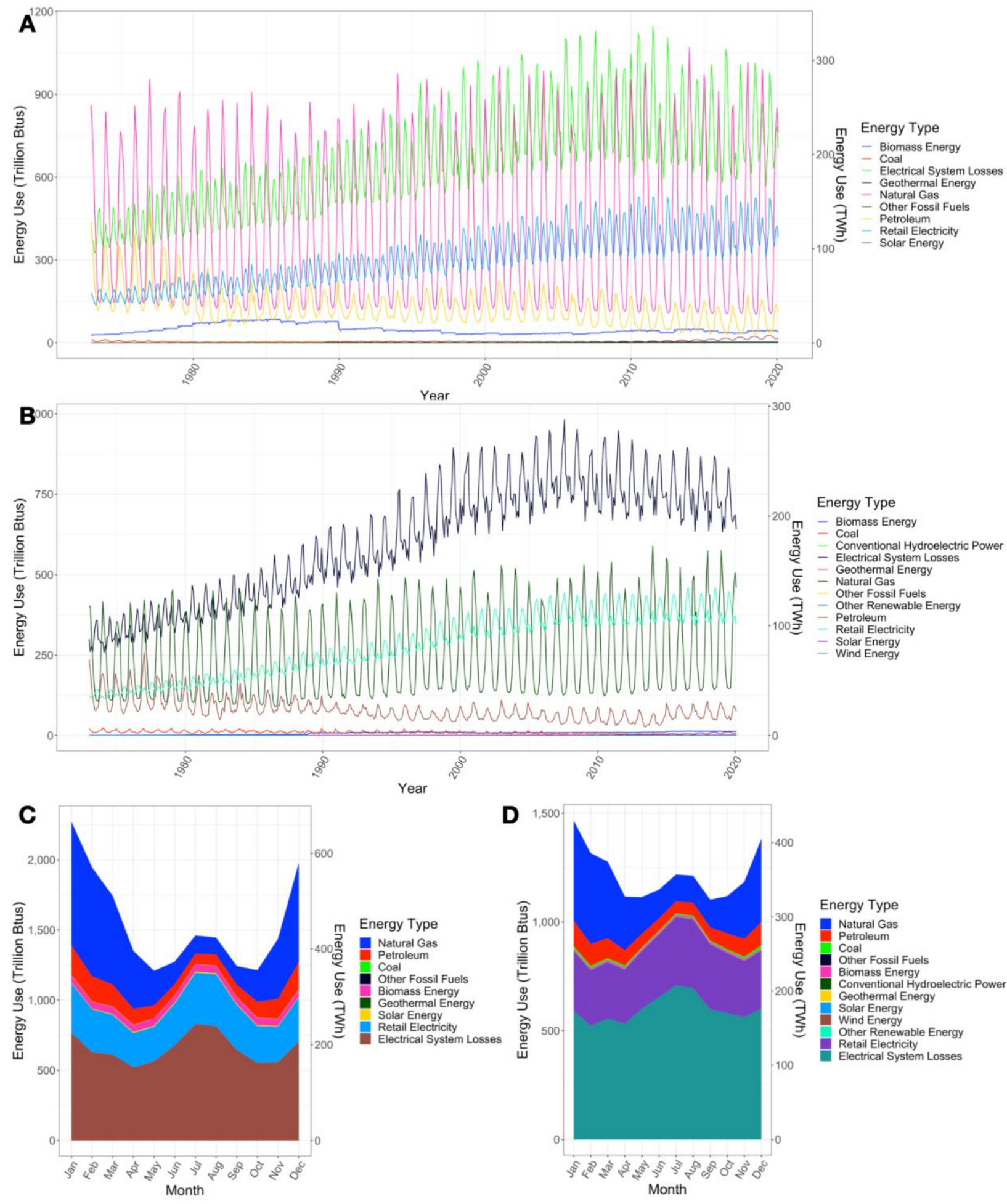
Figure 1: Energy consumption in buildings from January 1973 to February 2020. A)

2 Residential buildings; B) commercial buildings; C) monthly average in residential buildings; and

3 D) monthly average in commercial buildings.

5 The Role of Gas and Underground Gas Storage Facilities in Managing Seasonal

$6 \quad$ Fluctuations in Heating Energy Demand

8 Gas production and consumption across all sectors has stayed roughly the same from 1973 to

9 around 2005, and increased after 2005, largely due to the growth of shale gas (Fig 2A). Since

101973 , monthly average total consumption of gas peaks at 2,530 TBtus in January, and is lowest

11 in September, at 1,456 TBtus, with average seasonal fluctuation of 1,074 TBtus (Fig 2B). This

12 seasonal variation is largely driven by consumption in buildings, with a secondary peak in July

13 and August driven by electricity demand (Fig 2B). However, gas production is fairly flat

14 throughout the year, along with consumption in other sectors (Fig 2B). This asynchronicity

15 between gas production and consumption is largely managed by a network of 412 UGS

16 facilities, 388 of which were active in $2019^{16}$. Around $14 \%$ of all gas produced in the U.S.

17 annually is injected into UGS facilities for storage during the warmer months (April to October)

18 and withdrawn from storage during the cooler months (November to March) ${ }^{9,11,16}$. During the

19 average November-March heating season, 2,341 TBtus is withdrawn from UGS facilities in

20 total- $21 \%$ of total gas consumption during those months. UGS has a strong role in balancing

21 production and consumption of gas (regression $r^{2}=0.91$ with UGS, and $r^{2}=0.37$ without UGS).

22 UGS is equivalent to a battery with 686 TWh of heat storage capacity, and peak discharge rate

23 of $277 \mathrm{GW}$ of heat. For comparison, at the end of 2018 in the U.S., the total power capacity of

24 the U.S. grid-scale electric battery fleet was $869 \mathrm{MW}$, with a total electric storage capacity of

$251,236 \mathrm{MWh}^{17}$. This does not include additional backup capacity, as the UGS fleet tends to keep 
1 reserves -monthly average stored working gas peaks in October at 3,395 TBtus, and is lowest 2 in March at 1,529 TBtus.

3 

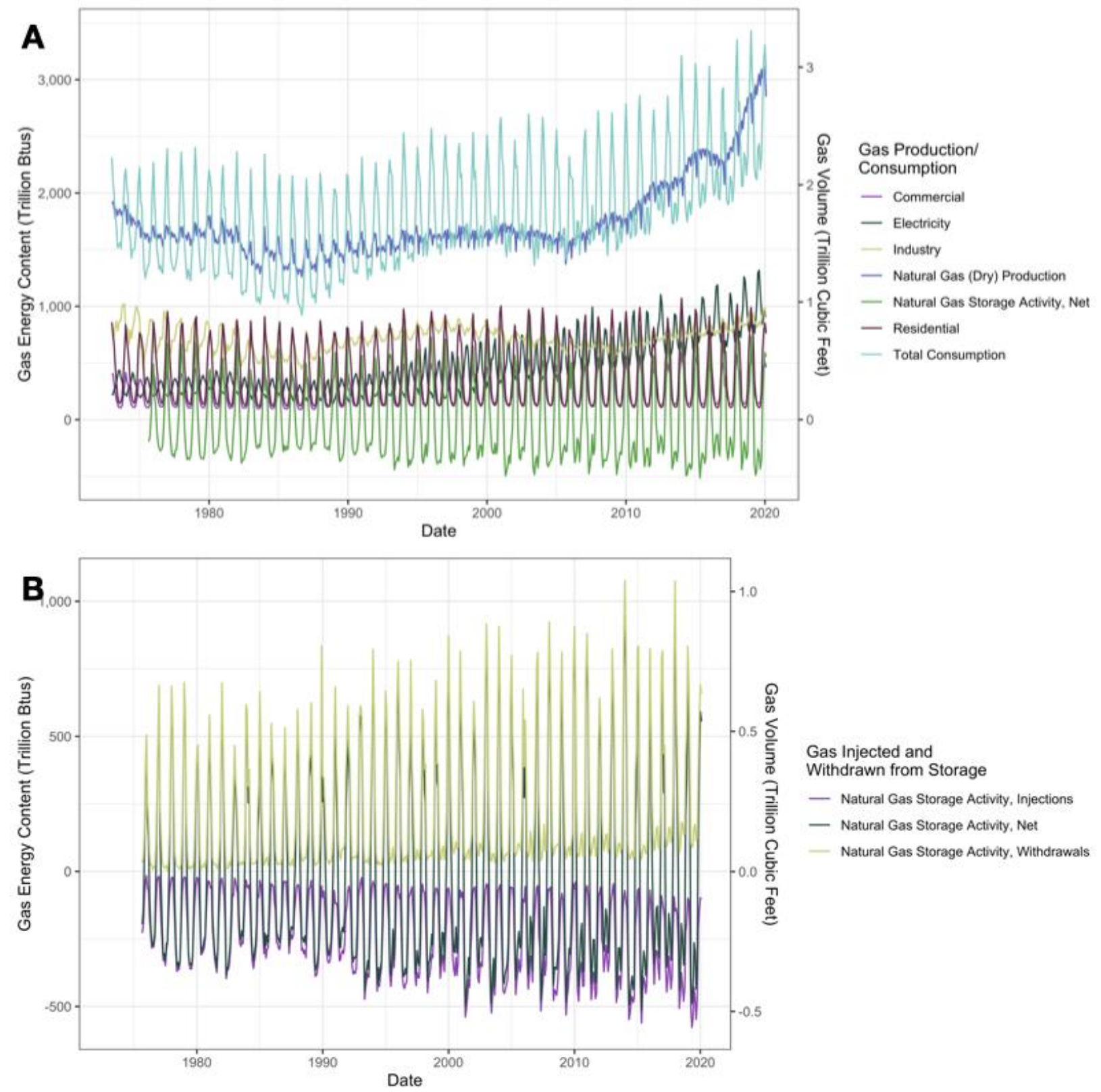

Gas Injected and Withdrawn from Storage - Natural Gas Storage Activity, Injections - Natural Gas Storage Activity. Net - Natural Gas Storage Activity. Withdrawals

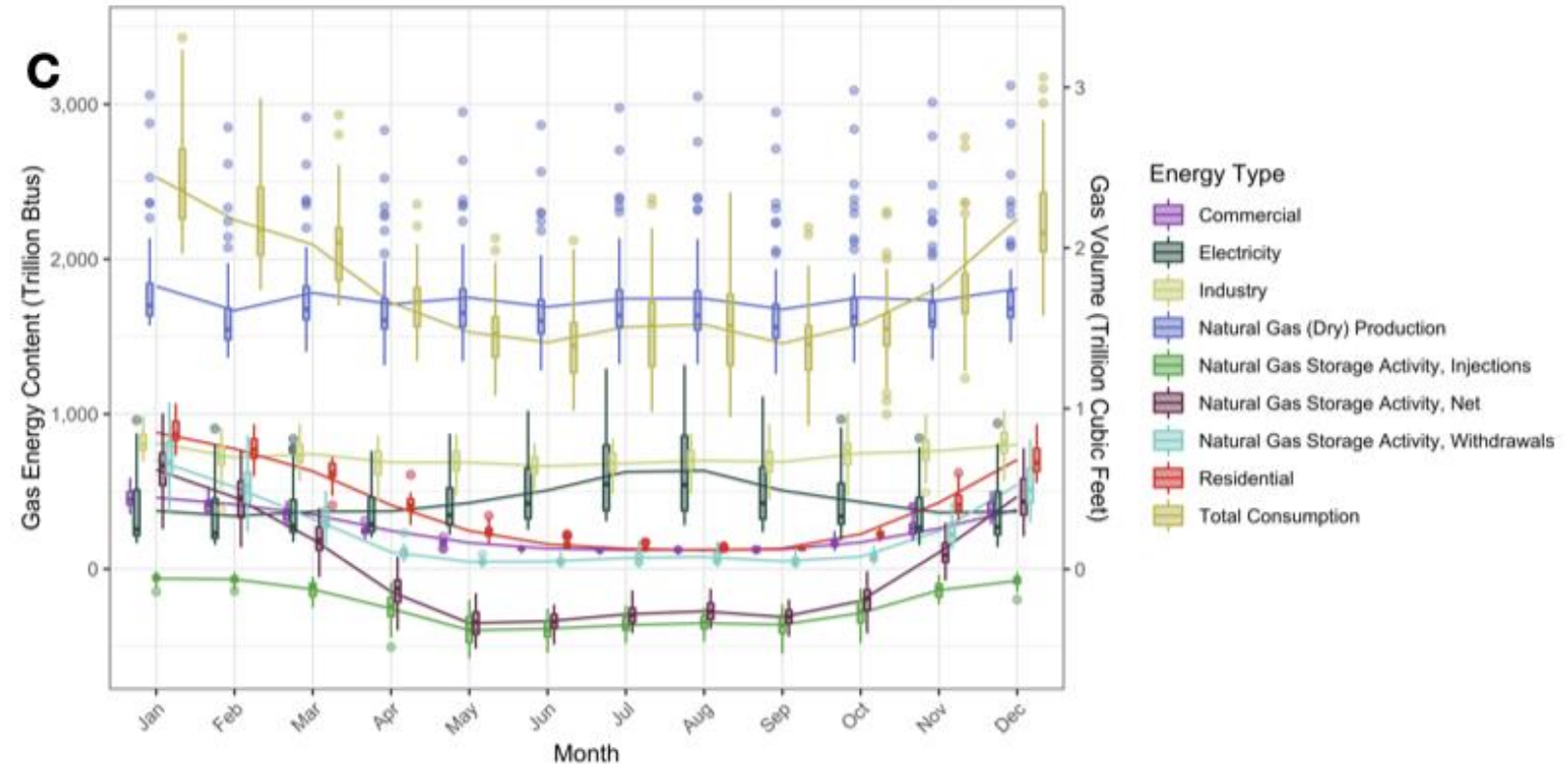


2 Figure 2: U.S. natural gas production, consumption, and storage from January 1973 to

3 February 2020. A) Monthly gas production and consumption; B) monthly gas storage activity;

4 and C) monthly average gas flows.

5

6 The "Falcon Curve" under Different Electrification Scenarios

7

8 Building energy demand fluctuates monthly, with a peak in winter that is a mixture of electricity

9 and on-site fossil fuel use, a secondary summer peak that is largely electricity, and is lowest in

10 the spring and fall months (Figure 3A). The shape of the falcon curve varies under different

11 hypothetical scenarios of building electrification (Figure 3A-3F). From March of 2010 through

12 February of 2020 , current monthly average total primary energy demand from buildings peaks in

13 January, at 4,271 TBtus, and is lowest in May, at 2,722 TBtus (Fig 3A) -a 1,549 TBtus

14 seasonal fluctuation. Electricity demand peaks in the summer 2,883 TBtus in July (including

$15 \sim 66 \%$ losses from power plant losses and direct use, along with transmission losses), has a

16 secondary peak at 2,496 TBtus in January, and is lowest in April at 1,943 TBtus (Fig 3A),

17 making a seasonal fluctuation of 940 TBtus. If $50 \%$ of current fossil building heating demand is

18 met with technologies with a COP of $1^{14}$, total seasonal fluctuation in total energy demand

19 would expand to 2,715 TBtus from September to January. The additional demand on the

20 electrical grid from electrifying heating would be enough to shift building demand from a summer

21 peak to a winter peak, with 4,917 TBtus in January, 3,360 TBtus in July, and 2,857 TBtus in

22 May (Fig 3B). If $100 \%$ of current fossil building energy is converted, the fluctuation in total

23 energy demand expands to 3,980 TBtus-3,430 TBtus in September to 7,410 TBtus in January

24 (Fig 3C). The expanse of this gap decreases as the COP for space heating technology

25 increases (Fig 3B-3F). With a COP of $6^{12,15}$, the seasonal fluctuation in total energy demand 
1 decreases to 1,022 TBtus-a peak of 3,375 TBtus in January, 3,122 TBtus in July, and 2,353

2 TBtus in April.

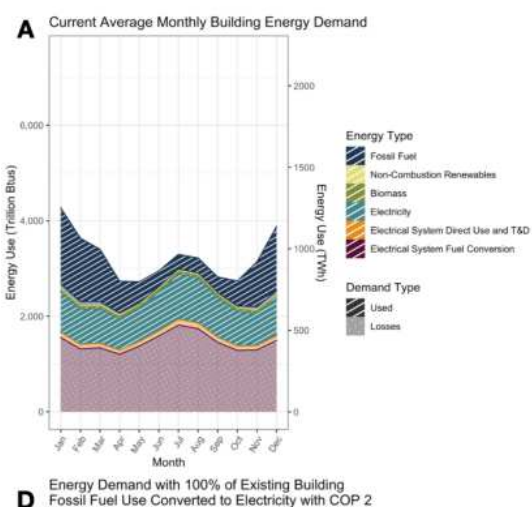

Energy Demand with $100 \%$ of Existing Building
Dossil Fuel Use Converted to Electricity with COP 2

4

5

Managing the Falcon Curve on the Electrical Grid

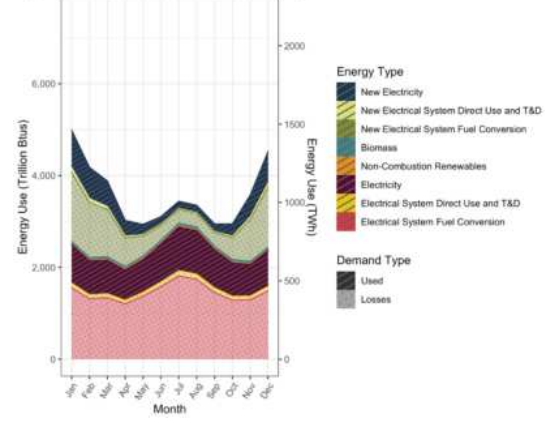
using technologies with a COP of 6.
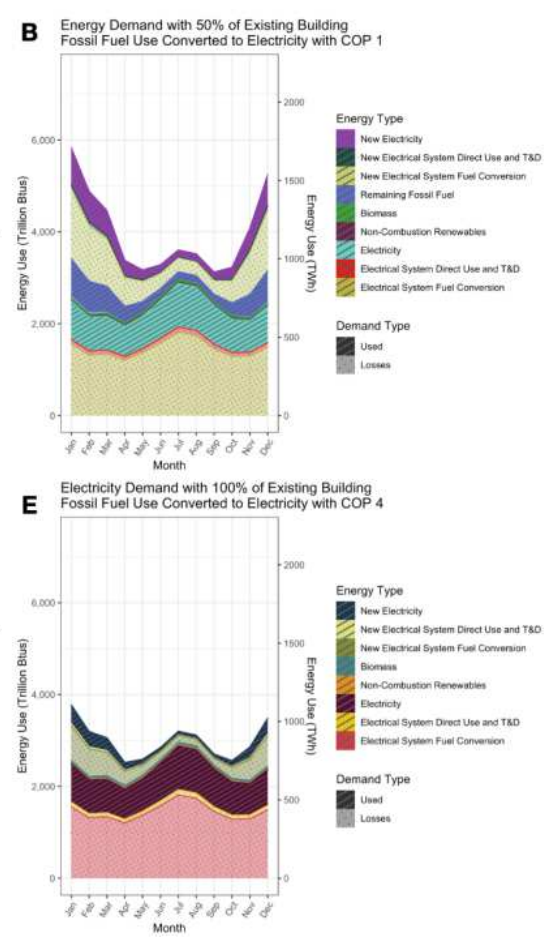

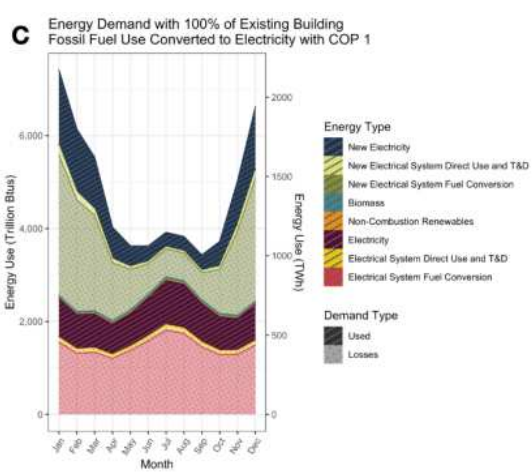

Energy Demand with $100 \%$ of Existing Building
Fossil Fuel Use Converted to Electricity with COP 6

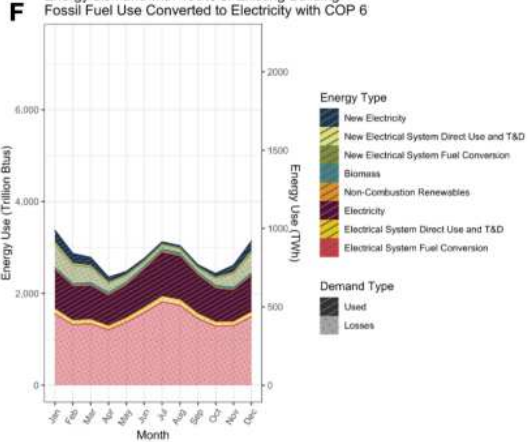

Figure 3: The "Falcon Curve"-Monthly average building total energy consumption from March 2010 to February 2020, and changes to building energy demand under different scenarios of building electrification with the current electrical grid. A) current-all buildings' energy demand. B-E are scenarios representing electrification of fossil energy use at B) $50 \%$ conversion using technologies with a coefficient of performance (COP) of 1 ; C) $100 \%$ conversion using technologies with a COP of 1 ; D) $100 \%$ conversion using technologies with a COP of 2; E) $100 \%$ conversion using technologies with a COP of 4; and F) $100 \%$ conversion 
1 Even under our most efficient scenario, using technologies with a COP of 6 , electrifying building

2 heating will put substantial additional demand on the electrical grid (Fig 4A), effectively

3 superimposing the falcon curve onto the electrical grid. Currently, January electrical demand is

4338 TWh. Under full building electrification with technologies with a COP of 1, total January

5 demand increases by 534 TWh, to 872 TWh, surpassing the summer peak. With technologies

6 with a COP of 6 , total demand in January increases by 89 TWh ( 21\%) to $427 \mathrm{TWh}$, higher than

7 the summer peak. Even under the most efficient prototypical COP, building electrification

8 presents a fundamental shift in electrical grid seasonal dynamics, from a summer peak to a

9 winter peak.

11 Currently, seasonal fluctuations in electricity demand are largely handled by coal and gas (Fig

12 4B). If the additional electricity demand from building electrification is met with electricity

13 generation resembling the current grid, combustion emissions will shift from buildings to power

14 plants. This can be avoided by generating this electricity from renewables. To provide some

15 illustrative scenarios of how electricity generation could be met with renewables, we model

16 scenarios where this demand is met by scaling up either wind or solar energy, using the existing

17 monthly generation profiles (Fig 4C). Meeting the 534 TWh gap in January electricity demand

18 that would result with electrification using technologies with COP of 1 with wind would require

19 scaling up wind from the average of $\sim 19$ TWh generation in January by a factor of $\sim 28 \mathrm{x}$ (Fig

$204 \mathrm{D})$. With a COP of 6 , this demand could be met by increasing current wind generation by a

21 factor of $\sim 4.5 \mathrm{x}$ (Fig 4D). In both scenarios, this would result in electricity generation exceeding

22 supply in some months. With technologies with a COP of 1 , grid generation would exceed

23 demand by, at its highest, roughly $1.8 \mathrm{x}$ in April, when demand is low and wind generation is

24 high. With COP of 6 , grid generation exceeds demand by only $20 \%$ (Fig 4D). If this is met by

25 solar, with technology with COP 1 , January solar generation would have to increase by a factor

26 of $\sim 303 \times$ (Fig $4 E$ ). With technology with a COP of 6 , January solar generation would only have 
1 to increase by a factor of $\sim 36 \mathrm{x}$ to meet January demand (Fig 4E). With COP of 1 , generation

2 exceeds demand by a factor of $2.9 x$ in June (Fig 4E); with COP of 6 , June generation exceeds

3 demand by $\sim 40 \%$ (Fig 4E). In all scenarios, the amount of overgeneration in off-peak months

4 and the need for renewable energy deployment could be reduced by deployment of seasonal-

5 scale electricity storage technologies.

6

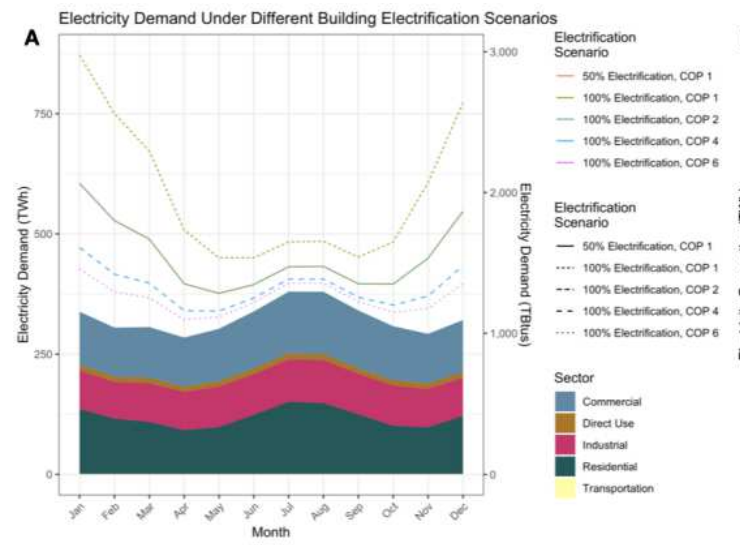

D Electricity Generation if Gap is Met With Wind

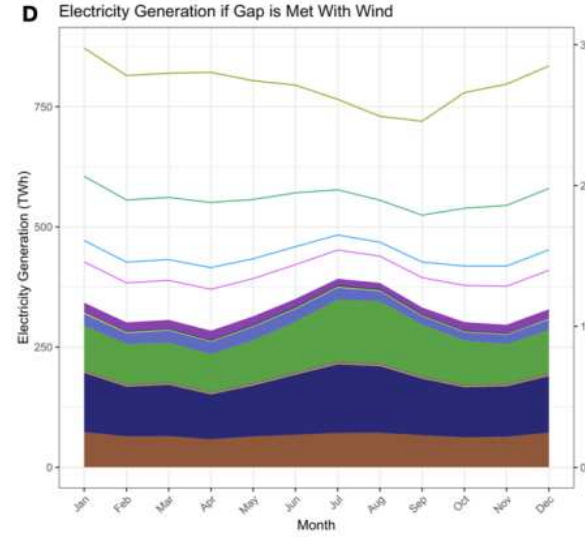

Current Average Monthly Electricity
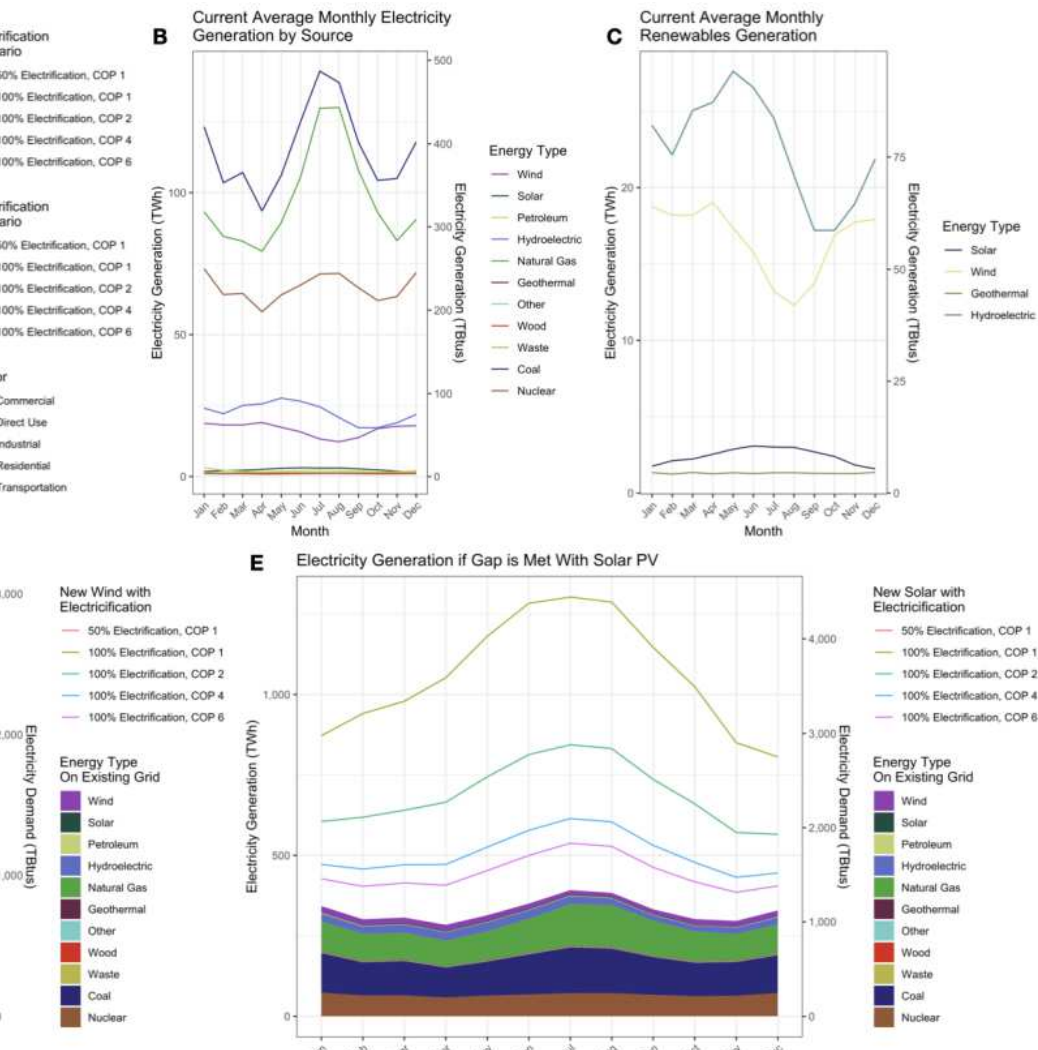

E Electricity Generation if Gap is Met With Solar PV

E Electricity Generation if Gap is Met With Solar PV

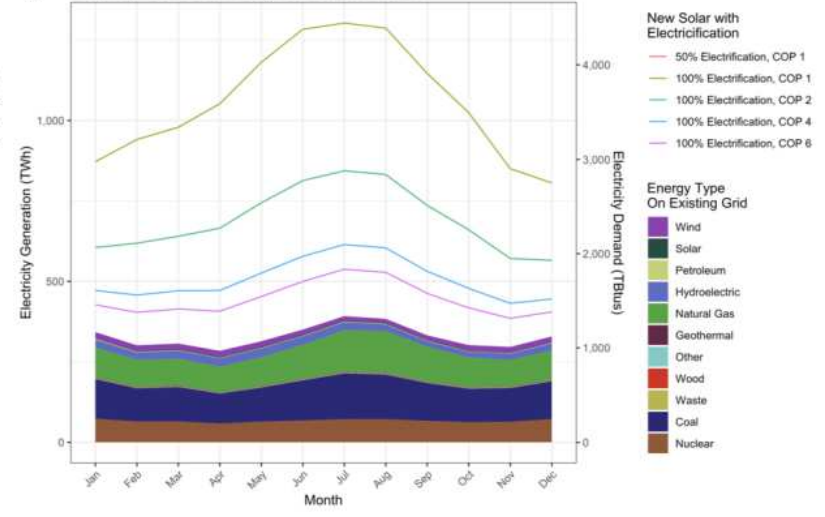

9 Figure 4: Electricity generation and demand from March 2010 to February 2020. A) current

10 total demand by sector and changes to demand under different building electrification scenarios;

11 B) current monthly average generation by fuel type; C) current monthly average generation from

12 non-combustion renewables; D) additional wind energy necessary to meet electricity demand

13 from building electrification; and E) additional solar energy necessary to meet electricity demand

14 from building electrification. 
3 We found a strong seasonal fluctuation in total energy consumption in the U.S., largely driven

4 by winter heating demand for buildings. This falcon curve is not represented in many of the

5 existing decarbonization pathways ${ }^{1,2,4-6}$. Currently, this fluctuation is managed largely by the

6 existing fleet of UGS and LNG facilities, and other storage capacity intrinsic to existing fossil fuel

7 energy systems. Electrifying building heating will superimpose the seasonal demand fluctuation

8 of the falcon curve to the electrical grid, increasing winter electricity demand enough to switch

9 electricity generation from summer peaking to winter peaking, similar to other studies that

10 incorporated seasonality of energy demand $5,14,18-22$. With the current grid, this demand would

11 likely be met by dispatchable electricity from gas and coal. Our results demonstrate that since

12 peak renewable energy production, especially solar, does not coincide with peak heating

13 demand, meeting this demand with renewables alone will require massive deployment of

14 renewables on top of existing fossil generation ${ }^{6,9,22}$.

16 Our analysis uses historical energy use data, so potential changes in future building heating

17 demand from factors including climate change, migration, building stock changes, and other

18 changes in building energy consumption are not included. Future energy policies, new

19 technologies for generation or storage, and electrification of other sectors may affect these

20 dynamics in the future. We also assume that all current use of fossil fuels in buildings could be

21 converted to electricity. The COPs used here are prototypical and intended for benchmarking-

22 they do not reflect changes in COPs due to diurnal, seasonal, and spatial variations of outdoor

23 temperatures, especially relevant for air source heat pumps (ASHP) during winter ${ }^{12-15,23}$. That

24 said, our analyses of the historical energy system performance reveal the extent of the seasonal

25 fluctuations in current total building energy demand and the role that fuel storage, especially 
1 from UGS, has in managing the falcon curve currently. Successfully electrifying buildings will

2 require replacing or bypassing this existing storage capacity.

4 There are a number of strategies that can be used to manage the falcon curve. High COP

5 heating and cooling technologies—such as ASHPs, ground source heat pumps (GSHPs), and

6 networked GSHPs - can flatten the falcon curve on the building demand side by reducing the

7 winter peak in electricity demand, reducing demand placed on the electrical grid. Passive and

8 active building energy efficiency, peak-shaving, and energy storage in buildings can also

9 support this. Dispatchable renewable energy and large-scale deployment of seasonal electricity

10 storage of capacity similar to existing UGS facilities are viable strategies for managing the

11 demand placed on the electrical grid. However, grid-based storage on this scale is beyond the

12 scope of the current design space ${ }^{24,25}$.

14 To avoid unintended adverse consequences for climate, health, and environmental justice,

15 building electrification and grid electricity need to be planned in tandem. For building

16 electrification to maximize reductions in GHG and air pollutant emissions and make the most

17 progress toward environmental justice, induced electricity demand should be met with non-

18 combustion renewables. Conversion of current on-site fossil fuel use to combustion of

19 renewable natural gas, hydrogen, biomass, or other renewable fuels either on-site or for

20 electricity generation, may perpetuate the air pollution and health burden of building energy use,

21 even if these fuels are truly GHG neutral ${ }^{3,26,27}$. Future decarbonization pathway development

22 should incorporate seasonal fluctuations in building energy demand, and model scenarios for

23 buildings and the electrical grid in tandem, in order to ensure that the electrical grid is capable of

24 meeting building demand for space heating. Additionally, deployment, field testing, and further

25 development of high-COP building heating and cooling technologies now can begin to flatten 
1 the falcon now, putting the building energy system on a trajectory well-aligned toward a zero-

2 emissions future.

\section{References}

6 1. International Energy Agency. Net Zero by 2050 - A Roadmap for the Global Energy Sector. $7224(2021)$.

8 2. Committee on Accelerating Decarbonization in the United States, Board on Energy and 9 Environmental Systems, Division on Engineering and Physical Sciences, \& National 10 Academies of Sciences, Engineering, and Medicine. Accelerating Decarbonization of the 11 U.S. Energy System. 25932 (National Academies Press, 2021). doi:10.17226/25932.

12 3. Buonocore, J. J., Salimifard, P., Michanowicz, D. R. \& Allen, J. G. A decade of the U.S. energy mix transitioning away from coal: historical reconstruction of the reductions in the

4
public health burden of energy. Environ. Res. Lett. 24 (2021)

5 doi:https://doi.org/10.1088/1748-9326/abe74c.

6 4. U.S. Energy Information Administration. Annual Energy Outlook 2021.

17 https://www.eia.gov/outlooks/aeo/pdf/AEO_Narrative_2021.pdf (2021).

5. White, P. R., Rhodes, J. D., Wilson, E. J. H. \& Webber, M. E. Quantifying the impact of residential space heating electrification on the Texas electric grid. Applied Energy 298, $117113(2021)$.

21 6. Williams, J. H. et al. Carbon-Neutral Pathways for the United States. AGU Advances 2,

23 7. Energy Information Administration (EIA). Commercial Buildings Energy Consumption 24 Survey (CBECS) Data.

25 https://www.eia.gov/consumption/commercial/data/2018/index.php?view=characteristics 26 (2018). 
1 8. Energy Information Administration (EIA). Residential Energy Consumption Survey (RECS).

2 https://www.eia.gov/consumption/residential/data/2015/ (2015).

3 9. U.S. Energy Information Administration. Total Energy Monthly Data.

$4 \quad$ https://www.eia.gov/totalenergy/data/monthly/index.php.

5 10. Michanowicz, D. R. et al. A national assessment of underground natural gas storage:

6 identifying wells with designs likely vulnerable to a single-point-of-failure. Environ. Res. Lett.

$7 \quad$ 12, 064004 (2017).

8 11. Natural Gas Storage Dashboard. https://www.eia.gov/naturalgas/storage/dashboard/.

9 12. Im, P. \& Liu, X. Energy Performance Evaluation of a Recycled Water Heat Pump System in

10 Cool and Dry Climate Zone. in Proceedings of the IGSHPA Technical/Research Conference

11 and Expo 2017 (International Ground Source Heat Pump Association, 2017).

12 doi:10.22488/okstate.17.000524.

13 13. Liu, X., Anderson, A., Hughes, P. \& Spitler, J. An Updated Assessment of the Technical

14 Potential of Geothermal Heat Pump Applications in the United States. 9.

15 14. Jadun, P. et al. Electrification Futures Study: End-Use Electric Technology Cost and

16 Performance Projections through 2050. 108 https://www.nrel.gov/docs/fy18osti/70485.pdf

17 (2017).

18 15. Buffa, S., Cozzini, M., D’Antoni, M., Baratieri, M. \& Fedrizzi, R. 5th generation district

19 heating and cooling systems: A review of existing cases in Europe. Renewable and

20 Sustainable Energy Reviews 104, 504-522 (2019).

21 16. U.S. Energy Information Administration. Natural Gas Annual Respondent Query System

22 (EIA 191).

$23 \mathrm{https}$ :/www.eia.gov/naturalgas/ngqs/\#?report=RP7\&year1=2019\&year2=2019\&company=N

24 ame.

25 17. Battery Storage in the United States: An Update on Market Trends. 33.

26 18. Bistline, J. E. T. The importance of temporal resolution in modeling deep decarbonization of 
the electric power sector. Environ. Res. Lett. 16, 084005 (2021).

2 19. Bistline, J. E. T., Roney, C. W., McCollum, D. L. \& Blanford, G. J. Deep decarbonization

3 impacts on electric load shapes and peak demand. Environ. Res. Lett. 16, 094054 (2021).

4 20. Ardani, K. et al. Solar Futures Study. 310.

5 21. Wei, M. et al. Deep carbon reductions in California require electrification and integration

$6 \quad$ across economic sectors. Environ. Res. Lett. 8, 014038 (2013).

7 22. Tarroja, B. et al. Translating climate change and heating system electrification impacts on

8 building energy use to future greenhouse gas emissions and electric grid capacity

9 requirements in California. Applied Energy 225, 522-534 (2018).

10 23. Goetzler, W., Guernsey, M. \& Kar, R. Research and Development Roadmap. Geothermal

11 (Ground-Source) Heat Pumps. DOE/EE--0810, 1219848

12 http://www.osti.gov/servlets/purl/1219848/ (2012) doi:10.2172/1219848.

13 24. Sepulveda, N. A., Jenkins, J. D., de Sisternes, F. J. \& Lester, R. K. The Role of Firm Low-

14 Carbon Electricity Resources in Deep Decarbonization of Power Generation. Joule 2, 2403$152420(2018)$

16 25. Sepulveda, N. A., Jenkins, J. D., Edington, A., Mallapragada, D. S. \& Lester, R. K. The 17 design space for long-duration energy storage in decarbonized power systems. Nat Energy 18 (2021) doi:10.1038/s41560-021-00796-8.

19 26. Dedoussi, I. C., Eastham, S. D., Monier, E. \& Barrett, S. R. H. Premature mortality related to $20 \quad$ United States cross-state air pollution. Nature 578, 261-265 (2020).

21 27. Lewis, A. Pollution from hydrogen fuel could widen inequality. Nature 595, 353-353 (2021). 


\section{Supplementary Files}

This is a list of supplementary files associated with this preprint. Click to download.

- TheSeasonalStorageGapMethodsforNatureEnergy.pdf 